\title{
Behavioral, Biochemical, Histological, and Electrophysiological Effects of 192 IgG-Saporin Injections into the Basal Forebrain of Rats
}

\author{
Gary L. Wenk, ${ }^{1}$ James D. Stoehr, ${ }^{1}$ George Quintana, ${ }^{1}$ Sherri Mobley, ${ }^{1}$ and Ronald G. Wiley ${ }^{2}$ \\ ${ }^{1}$ Arizona Research Laboratories, Division of Neural Systems, Memory and Aging, University of Arizona, Tucson, Arizona \\ 85724 and ${ }^{2}$ DVAMC and Vanderbilt University, Nashville, Tennessee 37232
}

The behavioral, biochemical, histological, and electrophysiological effects of a basal forebrain injection of saporin, a ribosome-inactivating protein, coupled to a monoclonal antibody against the low-affinity NGF receptor (192 lgG) were investigated in adult rats. Within the basal forebrain region, the low-affinity NGF receptor is exclusively expressed by cholinergic neurons in the medial septal area, diagonal band, and nucleus basalis magnocellularis (NBM). The presence of this receptor upon these cells confers a degree of specificity to the 192 IgG-saporin that could not previously be achieved by previous lesioning techniques, such as excitatory amino acids.

Rats with unilateral injections of different amounts of 192 IgG-saporin were prepared to determine the optimal conditions in order to produce a lesion restricted to the NBM that would not destroy cholinergic afferents to hippocampus or nearby regions. Electroencephalographic (EEG) recordings were taken from these lesioned rats before and during treatment with scopolamine ( $1 \mathrm{mg} / \mathbf{k g}$, i.p.).

Another group of rats received bilateral NBM injections of 192 lgG-saporin and were behaviorally tested using a rewarded, delayed-alternation task on a T-maze and a passive avoidance task. Finally, histological and biochemical investigations confirmed the effectiveness and specificity of the 192 lgG-saporin.

The results showed that the 192 IgG-saporin did not destroy neurotensin, galanin, somatostatin, NADPH-diaphorase, or neuropeptide $Y$ neurons within the NBM. Also, biomarkers of cholinergic function were significantly decreased throughout the neocortex and within the NBM, but not in the olfactory bulbs, hippocampus, or dorsal caudate nucleus. Intraperitoneal injections of scopolamine, but not NBM injections of 192 IgG-saporin, increased total power across all frequency bands; however, slow-wave frequencies showed a greater increase in power as compared to fastwave frequencies. Acquisition, and performance of the de-

\footnotetext{
Received Nov. 29, 1993; revised Feb. 28, 1994; accepted Mar. 29, 1994.

This work is dedicated to the memory of Dr. David S. Olton, whose guidance and inspiration made these studies possible. G.L.W. thanks Drs. Carol Barnes and Cindy Erickson for their valuable assistance with the EEG studies, and Ms. Jennifer Gurney and Mr. Chad Livdahl for their excellent assistance in conducting the behavioral testing. This work was supported by The National Science Foundation, BNS 89-14941.

Correspondence should be addressed to Dr. Gary L. Wenk, Division of Neural Systems, Memory and Aging, 384 Life Sciences North, University of Arizona, Tucson, AZ 85724

Copyright (C) 1994 Society for Neuroscience $0270-6474 / 94 / 145986-10 \$ 05.00 / 0$
}

layed-alternation or passive avoidance tasks were not impaired by the lesions.

These data confirm the effectiveness and specificity of this novel lesioning tool and suggest that selective loss of NBM cholinergic cells is not sufficient to impair performance in these behavioral tasks.

[Key words: 192 IgG-saporin, nucleus basalis, EEG, basal forebrain, lesion, T-maze alternation, rats]

Loss of neurons in the basal forebrain may play an important role in the cognitive deficits associated with aging and Alzheimer's disease (Bartus et al., 1982). The basal forebrain region includes the medial septum, vertical and horizontal limbs of the diagonal band of Broca, and the nucleus basalis magnocellularis (NBM) (Mesulam et al., 1983). Basal forebrain lesions produce behavioral deficits in both monkeys and rats (for a review, see Olton and Wenk, 1987) and increase the incidence of slow-wave activity in neocortical EEG recordings in rats (Stewart et al., 1984; Buzsaki et al., 1988; Riekkinen et al., 1990a,b). These lesions are frequently produced by microinjection of glutamate analogs such as ibotenic (IBO) or quisqualic (QUIS) acid. Both IBO and QUIS effectively destroy cholinergic cells within the basal forebrain, but only IBO impairs performance in behavioral tasks that require learning and memory (Dunnett et al., 1987; Etherington et al., 1987; Everitt et al., 1987; Markowska et al., 1990; Riekkinen et al., 1991; Wenk et al., 1992). This suggests that the memory impairments are not related to the cholinergic cell loss but may be related to the loss of noncholinergic cells within the basal forebrain (Riekkinen et al., 1990a,b; Dunnett et al., 1991; Sarter and Dudchenko, 1991; Wenk et al., 1992), such as GABA, substance P (SP), neurotensin (NT), leu-enkephalin (LE), somatostatin (SOM), galanin, or neuropeptide $Y$ (NPY) (Candy et al., 1985). The resolution of the role of basal forebrain cholinergic cells in mnemonic processes has been hampered by the lack of a specific method for selectively destroying cholinergic neurons. The lack of specificity of IBO and QUIS has precluded a clear interpretation of the behavioral data.

The nonspecificity of neurotoxins has also prevented a clear interpretation of the effects of basal forebrain lesions upon neocortical EEG activity. Recent reports found a pronounced increase in large-amplitude, slow-wave activity predominating in the neocortex ipsilateral to a unilateral lesion (Stewart et al., 1984; Buzsaki et al., 1988; Riekkinen et al., 1990a,b; Vanderwolf et al., 1993). While correlations were found between the increase in slow-wave activity and cortical ChAT loss, the amount of incidental and nonspecific damage to noncholinergic fore- 
brain neurons may also underlie the changes in EEG. Therefore, the use of a toxin that is specific for cholinergic neurons is required in order to determine whether the loss of NBM cholinergic neurons is solely responsible for cortical EEG slowing.

A powerful new approach to selective neural lesioning uses antineuronal immunotoxins (Wiley, 1992). In the present study, basal forebrain cholinergic cells were selectively destroyed by injection of an antineuronal immunotoxin recently developed by Wiley et al. (1991). This compound consists of a monoclonal antibody (192 IgG) to the low-affinity nerve growth factor (NGF) receptor that has been armed with the ribosome-inactivating protcin saporin. Injections of this $192 \mathrm{IgG}$-saporin complex produce long-lasting depletions in cholinergic markers throughout the forebrain (Book et al., 1992). The actual selectivity of this molecule remains to be fully defined. In the only published study, a single high-dose intracerebroventricular injection (4.69 $\mu \mathrm{g}$ of $192 \mathrm{IgG}$-saporin in $7.0 \mu \mathrm{l}$ ) reduced ChAT activity throughout the neocortex, hippocampus, and septal area (Nilsson et al., 1992). Endogenous levels of dopamine were unaffected by injections of $192 \mathrm{IgG}$-saporin, while endogenous levels of norepinephrine were elevated in the hippocampus and striatum. The lesion significantly impaired acquisition of the Morris water maze task. These data do not address the issue of which cholinergic neurons within the basal forebrain were responsible for the behavioral impairments, for example, the NBM, which innervates cortex, or the medial septal area, which innervates hippocampus, because 192 IgG-saporin destroyed both populations of cholinergic cells. Intracerebroventricular injections of $192 \mathrm{IgG}$-saporin also destroy a population of cerebellar Purkinje cells (Wiley, 1992); the influence of this cerebellar cell loss upon swimming ability, and thereby indirectly upon performance in the water maze, remains to be determined.

The present study was designed to investigate. whether the selective destruction of NBM cholinergic cells is associated with a learning and memory impairment. The basal forebrain region of male rats was microinfused with a small amount of 192 IgGsaporin. These rats were then tested in a food-motivated, delayed-alternation task on a T-maze and in a passive avoidance task. An EEG spectral analysis was also conducted. The brains of these rats were then analyzed by various neurochemical and histological methods to confirm the effectiveness and selectivity of the lesions produced by $192 \mathrm{IgG}$-saporin.

\section{Materials and Methods}

\section{Subjects}

Male Long-Evans rats (approximately $250 \mathrm{gm}$ at the beginning of testing) were doubly housed in plastic cages with ad lib water. Two weeks after surgery, those rats that were behaviorally tested, that is, those with bilateral lesions, were food restricted to $85 \%$ of ad libitum body weight. Thirty minutes after each day's testing session, each rat was given, in his cage, sufficient food to allow for a body weight increase of $5 \mathrm{gm}$ per week. Rats with unilateral lesions, for example, those involved in the EEG study, were not food deprived. All rats were on a 12:12 hr day: night cycle, with lights on at 0600 .

\section{Immunotoxin}

192 IgG-saporin was prepared as previously described (Wiley et al., 1991; Wiley and Lappi, 1993), dissolved in phosphate-buffered saline, and stored frozen $\left(-70^{\circ} \mathrm{C}\right)$ until use.

\section{Surgery}

Each rat was first given an intraperitoneal injection of atropine methylbromide $(0.5 \mathrm{mg})$, anesthetized with sodium pentobarbital $(50 \mathrm{mg} /$ $\mathrm{kg}$, i.p.), and placed in a stereotaxic instrument (model 900, Kopf In- struments, Tujunga, CA) with the incisor bar set $2.0 \mathrm{~mm}$ below the ear bars (flat skull). The scalp was incised and retracted and holes were drilled in the skull with a dental drill.

Unilateral lesion study. The results of these unilateral lesion studies guided the choice of lesion coordinates for the behavioral studies that used bilateral lesions. The purpose of this study was to determine the optimal concentration of $192 \mathrm{IgG}$-saporin that would destroy the greatest number of NBM cholinergic cells with the least amount of cell loss in the horizontal limb of the diagonal band of Broca, the dorsal and ventral aspects of the basal ganglia, and other surrounding structures that may receive cholinergic innervation, for example, the olfactory bulbs. Our preliminary studies had already investigated the optimal volume and anterior-posterior coordinates that would preclude extensive spread of the 192 IgG-saporin and injury to medial septal and diagonal band neurons, respectively (data not shown). The unilateral lesion coordinates were as follows: $0.9 \mathrm{~mm}$ posterior to bregma, 2.8 $\mathrm{mm}$ lateral from the midline (left or right side), and $6.9 \mathrm{~mm}$ below the dura for all rats. The amounts of 192 IgG-saporin tested were 5, 10, and $22.5 \mathrm{ng}$ injected in a constant total volume of $0.03 \mu \mathrm{l}$.

Behavioral study. Bilateral lesion coordinates for the behavioral study were $0.9 \mathrm{~mm}$ posterior to dregma, $2.8 \mathrm{~mm}$ lateral from the midline, and $6.9 \mathrm{~mm}$ below the dura. The $192 \mathrm{IgG}$-saporin $(10 \mathrm{ng}$ in $0.03 \mu \mathrm{l})$ was injected slowly (taking approximately $2 \mathrm{~min}$ ) and the needle was left in place for $5 \mathrm{~min}$ to limit diffusion dorsal to the injection site. This concentration of 192 IgG-saporin was chosen because the preliminary unilateral lesion study outlined above found that this concentration provided the greatest loss of cholinergic cells that project to cortex, without loss of hippocampal afferents, and with the most limited loss of striatal cholinergic cells. Control rats had the injection cannula lowered to the same coordinates but no injection was made.

The following postoperative procedures were performed at the completion of all surgeries: chloramphenicol ( $1 \%$ solution) was applied to the exposed skull and scalp prior to closure to limit local infection, lidocaine was applied locally to the scalp to lessen pain, $5 \mathrm{ml}$ of sterile isotonic saline was injected subcutaneously to prevent dehydration during recovery, and bicillin $(0.5 \mathrm{ml}, 300,000 \mathrm{U} / \mathrm{ml})$ was injected intramuscularly to prevent infection. Each rat was also given diluted Tylenol (cherry flavored) to drink for $24 \mathrm{hr}$ after surgery to lessen postoperative pain.

\section{Behavioral testing}

$T$-maze alternation task. Two weeks after recovery from surgery, the rats were tested in a food-motivated, delayed-alternation task in a T-maze using an apparatus previously described (Wenk et al., 1992). The task was chosen because it is sensitive to the cytotoxic effects of glutamate analogs, such as IBO (Wenk et al., 1989, 1992). Each rat was initially allowed to spend 30 min for 3 consecutive days on the maze eating the reward that was scattered around the maze. For the next $3 \mathrm{~d}$, each rat explored the maze for $30 \mathrm{~min}$ and found food only at the ends of the arms. Finally, for $3 \mathrm{~d}$ the rats were allowed to explore the maze and food was available only in food cups at the ends of each arm. Testing began on the 24th day after surgery. At the beginning of each test session, one piece of fond was placed at the end of one arm of the maze. The arm that contained food was varied randomly across sessions. For the first, forced trial, the side of the maze that did not contain food was blocked, which forced the rat to go to the baited side. After the rat ate the food he was placed back at the starting position and the block was removed. For all subsequent choice trials, food was placed on the side of the maze not entered by the rat on the previous trial. The rat was then allowed to choose between the two arms. If the rat entered the arm that contained the food a correct choice was recorded; the rat was allowed to eat the food and then returned to the starting position. If the rat entered the unbaited arm an error was recorded and the rat was placed back at the start without receiving any food. A rat received the maximum amount of reinforcement for choosing correctly on the first choice trial and then alternating responses between the two arms. Each rat was tested $6 \mathrm{~d}$ per week and received 10 choice trials per day with an interchoice interval of $5 \mathrm{sec}$. After performance had stabilized, the interchoice interval was increased to $15 \mathrm{sec}$ for the last $4 \mathrm{~d}$ of testing. The data were analyzed by a two-way ANOVA with repeated measures.

Step-through passive avoidance. All rats were tested on a step-through passive avoidance task during the fifth week following surgery. This task was chosen because it is sensitive to NBM lesions produced by injections of glutamate analogs (Dunnett et al., 1987). The training apparatus, $50 \times 48 \times 26 \mathrm{~cm}$, consisted of two operant chambers joined 
to one another and separated by a $10 \times 15 \mathrm{~cm}$ guillotine door. The light compartment was made of Plexiglas, had a Perspex floor, and was illuminated by an overhead $60 \mathrm{~W}$ lamp. The dark compartment was made of aluminum, had a floor composed of 18 grids that were connected to a shock generator and scrambler (Lafayette Instruments, Lafayette, IN), and had no illumination. Each rat was habituated to the box for two trials. On the first trial, each rat was placed in the illuminated compartment and allowed to explore the box. The latency to enter the dark compartment was recorded, and the door was closed, confining the rat for $15 \mathrm{sec}$ in the dark compartment before being returned to a holding cage. After $15 \mathrm{sec}$, the same procedure was repeated. After another $15 \mathrm{sec}$ in the holding cage, each rat was again placed in the illuminated compartment. Upon entering the dark compartment, the rat was given a $1 \mathrm{sec}, 0.5 \mathrm{~mA}$ scrambled footshock, kept in the dark compartment for $15 \mathrm{sec}$, and then transferred to a holding cage for 15 sec prior to being returned to the illuminated compartment for further training trials. Each rat was given repeated training trials with footshock on entry to the dark compartment until it reached a uniform acquisition criterion of not entering the compartment within $300 \mathrm{sec}$. Forty-eight hours later each rat was tested for retention. Each rat was placed in the illuminated compartment and the latency to enter the dark compartment was recorded, up to a maximum time of $1200 \mathrm{sec}$. During the retention test, the levels of conditioned freezing displayed by each rat were evaluated. Behavior was scored every $3 \mathrm{sec}$ as freezing (the lack of all visible body movements except for that necessitated by respiration) or as activity (all other behaviors, including rearing and grooming). The number of fecal boli were also counted to use as an additional index of fear. The data were analyzed by Student's $t$ test and linear regression analyses.

\section{Electrophysiology}

Each rat was prepared for surgery as described above (10 ng of $192 \mathrm{IgG}-$ saporin in $0.03 \mu \mathrm{l})$. After each rat received a unilateral NBM lesion, four EEG recording electrodes (self-tapping stainless steel jeweler's screws attached to Teflon-insulated wire) were inserted into the skull. All electrodes were $2.5 \mathrm{~mm}$ lateral to the midline and either $2.5 \mathrm{~mm}$ anterior or $3.5 \mathrm{~mm}$ posterior to bregma (according to the method described by Reikkinen et al., 1990). A fifth electrode was placed at lambda and served as ground. The reference electrode was placed $3.5 \mathrm{~mm}$ behind the ground electrode, on the midline. The electrodes and connecting male pins were embedded in dental acrylic. Four Mosfet input amplifiers mounted on the headstage served to eliminate cable movement artifacts.

EEG recordings were taken from freely moving rats between 1000 and $1600 \mathrm{hr}, 9-15 \mathrm{~d}$ after surgery. Bioelectrical activity was amplified 10,000 -fold, filtered $1-100 \mathrm{~Hz}$, and stored. Power was estimated using fast Fourier transformations (FFTs) of ten $2 \mathrm{sec}$, artifact-free epochs from each daily session and digitized using a sampling rate of $250 \mathrm{~Hz}$. EEG records that corresponded to an arousal state of drowsiness were used in an effort to maximize the overall effect of NBM lesions upon the EEG (G. Buzsaki, personal communication). Total power was determined for the $\delta(1-4 \mathrm{~Hz}), \theta(4-8 \mathrm{~Hz}), \alpha(8-12 \mathrm{~Hz})$, and $\beta(12-20 \mathrm{~Hz})$ bands. In rats with unilateral lesions, recordings were completed immediately before, and 20-30 min after, an intraperitoneal injection of scopolamine $\mathrm{HCl}(1 \mathrm{mg} / \mathrm{kg}$ in phosphate-buffered saline). The scopolamine challenge was performed in order to confirm whether the placement of the recording electrodes would allow for the detection of the significant slowing in EEG frequencies that is associated with scopolamine treatment (Buzsaki et al., 1998). The data were analyzed by ANOVA; planned post hoc comparisons of the data were made by Duncan's multiple range and Newman-Keuls tests.

\section{Biochemistry}

After behavioral testing was completed, each rat was killed by decapitation and the brain removed and placed in a cold $\left(4^{\circ} \mathrm{C}\right)$ Brain Matrix (model RBM-4000C, Activational Systems, Warren, MI) for dissection. A coronal section (approximately $2 \mathrm{~mm}$ thick) was taken to include the basal forebrain region. The most anterior extent of the $2 \mathrm{~mm}$ coronal slab was at the level of the anterior commissure. The basal forcbrain region, including the NBM and substantia innominata region, was isolated by two cuts made through the ventral pallidum and ventral substantia innominata, and a vertical cut made near the lateral border of the hypothalamus. The basal forebrain tissue section was rapidly frozen in cold $\left(-60^{\circ} \mathrm{C}\right)$ isopentane and stored $\left(-70^{\circ} \mathrm{C}\right)$ for radioimmunoassay (RIA) of somatostatin, neurotensin, and galanin. A small section of caudate nucleus (approximately $20 \mathrm{mg}$ ), dorsal to the previous section, was also taken from this slab. Tissue samples were also taken bilaterally from the frontolateral sensorimotor and parietal-occipital cortices, and stored $\left(-70^{\circ} \mathrm{C}\right)$ until assayed for choline acetyltransferase (ChAT) activity.

ChAT activity was measured by the formation of ${ }^{14} \mathrm{C}$-acetylcholine from ${ }^{14} \mathrm{C}$-acetyl coenzyme $\mathrm{A}$ and choline, according to the method of Fonnum (1969). Protein content was determined by the method of Lowry et al. (1951), with bovine serum albumin as the protein standard.

Frozen samples taken from the basal forebrain region of each rat were sunieated in ice-cold $\left(4^{\circ} \mathrm{C}\right) 0.1 \mathrm{M} \mathrm{HCl}$ and centrifuged $(20 \mathrm{~min}$ at 8160 $\times g$ ) in an Eppendorf microcentrifuge. Duplicate aliquots of the supernatant were frozen $\left(-80^{\circ} \mathrm{C}\right)$, lyophilized, and assayed for galanin, neurotensin, or somatostatin using commercial RIA kits (Peninsula Laboratories, Belmont, CA). ChAT activity and RIA data were analyzed by Student's $t$ test.

\section{Histology}

At least two rats from each group (unilateral and bilateral lesions and sham controls) were given lethal injections of sodium pentobarbital and prepared for in situ perfusion of the brain with $100 \mathrm{ml}$ of cold $\left(4^{\circ} \mathrm{C}\right)$ saline containing $1000 \mathrm{U}$ of heparin, followed by perfusion with cold $\left(4^{\circ} \mathrm{C}\right)$, filtered $3 \%$ paraformaldehyde in $0.1 \mathrm{M}$ sodium phosphate buffer (pH 7.3). The brain was removed and cryoprotected in $0.1 \mathrm{M}$ phosphate buffer containing $30 \%$ sucrose at $4^{\circ} \mathrm{C}$ for $24-48 \mathrm{hr}$, and then stored at $-80^{\circ} \mathrm{C}$. Coronal sections $(40 \mu \mathrm{m})$. were cut through the entire basal forebrain region on a freezing-sliding microtome. The sections were stained by NADPH-diaphorase histochemistry or by immunocytochemistry for the presence of ChAT- or NPY-positive cells.

NADPH-diaphorase activity was determined according to the method of Scherer-Singler et al. (1983). Briefly, free-floating, freshly cut sections were incubated for $1 \mathrm{hr}$ in $0.1 \mathrm{M}$ Tris- $\mathrm{HCl}, \mathrm{pH} 8.0$, containing $1.0 \mathrm{~mm}$ NADPH, $0.2 \mathrm{~mm}$ nitroblue tetrazolium, $0.04 \%$ Tween- $80,0.1 \%$ Triton $\mathrm{X}-100,1.0 \mathrm{~mm}$ magnesium chloride, and $15 \mathrm{~mm}$ sodium maleate (Sigma Chemical Co., St. Louis). Sections were then mounted on glass slides and examined by light microscopy.

For ChAT and NPY immunocytochemistry, the antibodies were buffered in $0.05 \mathrm{M}$ Tris-buffered saline (TBS). All sections were immersed in $0.4 \%$ Triton X-100 (Sigma) in TBS for $30 \mathrm{~min}$, followed by incubation in $4 \%$ normal goat serum ("blocker") (GIBCO-Bethesda Research Labs, Gaithersburg, MD) for $1 \mathrm{hr}$. Sections were placed directly into the primary antisera $(1: 150$, anti-rat choline acetyltransferase, Boehringer Mannheim, Indianapolis, IN; 1:1000, anti-NPY, Peninsula Labs), which was diluted with TBS $/ 0.1 \%$ Triton X- 100 with $2 \%$ blocker. Following incubations for $48 \mathrm{hr}$ at $4^{\circ} \mathrm{C}$, sections were washed in TBS (three times for $10 \mathrm{~min}$ each) and placed for $1 \mathrm{hr}$ in the secondary antibody [goat anti-mouse IgG $(\mathrm{H}+\mathrm{L}), 1: 100$; Jackson ImmunoResearch Labs, Inc. West Grove, PA] prepared in $0.1 \%$ Triton X-100 in TBS and $2 \%$ blocker. Sections were then rinsed (three times for $10 \mathrm{~min}$ each) in TBS and placed in mouse peroxidase-antiperoxidase $(1: 250)$ in TBS and 2\% blocker for $1 \mathrm{hr}$. Sections were washed (three times for $10 \mathrm{~min}$ each) in TBS. The sections were reacted in $0.05 \%$ diaminobenzidine (Sigma) in TBS for $7 \mathrm{~min}\left(20^{\circ} \mathrm{C}\right)$. The sections were then mounted onto chromealum-subbed slides, air dried at room temperature $\left(20^{\circ} \mathrm{C}\right)$, dehydrated through a graded series of alcohols and xylenes, and coverslipped.

\section{Results}

\section{Behavior}

\section{$T$-maze alternation task}

The performance of rats with or without basal forebrain lesions was similar across all days of testing. A two-way ANOVA (groups $x$ test sessions) of the behavioral data (Fig. 1) showed no main effect of groups $[F(1,31)=1.76, p>0.1]$, a main effect of test scssions $[F(15,31)=5.65, p<0.05]$ for both groups, and no significant interaction $(p>0.1)$.

\section{Step-through passive avoidance}

The number of trials to criterion, latencies to enter the dark chamber, and the total percentage of time spent freezing are shown in Table 1. There were no significant differences between the groups in the trials to criterion ( $p>0.1$ ), latencies in the $48 \mathrm{hr}$ retention test $(p>0.1)$, or total time spent freezing $(p>$ 


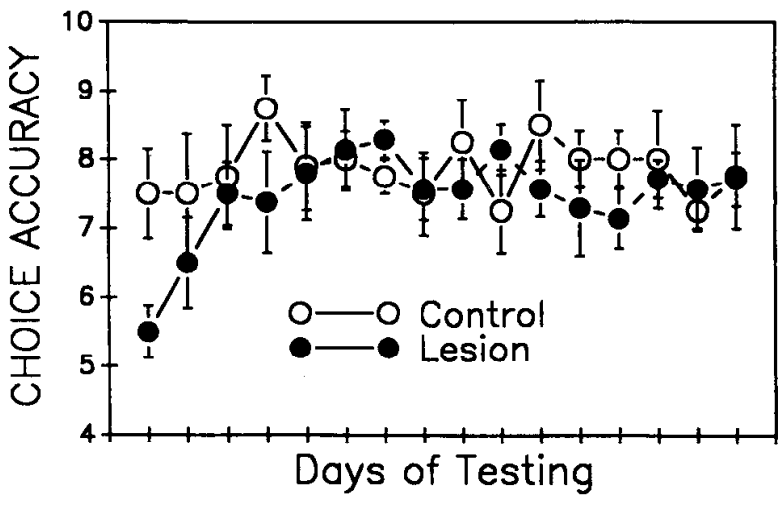

Figure 1. Performance of lesioned rats in a T-maze. The vertical axis represents the number of correct choices out of a possible 10. Data are expressed as the mean number of correct choices each day \pm SD for 16 d of testing. An ANOVA, with repeated measures, revealed no significant main effect due to the lesion.

0.1 ). Further analyses determined that a positive correlation existed between the latencies on the $48 \mathrm{hr}$ retention test and freezing behavior $(r=+0.84, p<0.005)$. There were no significant differences between groups in the number of fecal boli during the retention test.

\section{Electrophysiology}

Analysis of the EEG power spectrum for four frequency ranges, that is, $\delta, \theta, \alpha$, and $\beta$, found that the lesions did not produce any significant changes in the amount of slow- or fast-wave activity $[F(3,52)=0.2, p>0.1]$. In addition, NBM lesions, either bilateral or unilateral, did not produce an increase in the number or duration of high-voltage spindles. A correlational analysis between the decline in cortical (sensorimotor) ChAT activity and the difference in EEG power $(1-4 \mathrm{~Hz})$ between lesioned and unlesioned hemispheres was not significant $(r=-0.03, p>$ 0.1 ). ANOVAs revealed a significant $(p<0.01)$ effect of the scopolamine treatment across all frequency bands over frontal $[F(3,52)=23.8(\delta), 29.4(\theta), 22.4(\alpha), 9.9(\beta)]$ and parietal $[F(3,52)$ $=19.1(\delta), 26.7(\theta), 9.3(\alpha), 3.4(\beta)]$ cortical regions in both control and lesioned rats (Fig. 2). Although scopolamine significantly incrcased total power across all frequency bands, it produced a significantly greater increase in the $\delta$ and $\theta$ frequencies compared to $\alpha$ and $\beta$ frequencies over frontal cortical regions of both control $[F(3,36)=13.9, p<0.01]$ and lesioned $[F(3,36)$ $=10.8, p<0.01]$ rats, as well as over parietal cortical regions in both control $[F(3,36)=10.7, p<0.01]$ and lesioned $[F(3,36)$ $=6.1, p<0.01]$ rats.

\section{Biochemistry}

\section{ChAT activity}

Unilateral lesions. Injection of $192 \mathrm{IgG}$-saporin into the basal forebrain significantly decreased the ChAT activity in the frontolateral sensorimotor, and parietal-occipital cortex, striatum, and olfactory bulbs in a dose-dependent manner (Table 2), relative to the uninjected side. Levels of ChAT activity in the hippocampus, caudate nucleus, and olfactory bulbs were unaffected by injection of the two lowest doses of $192 \mathrm{IgG}$-saporin. Levels of ChAT activity in the caudate nucleus and hippocampus were significantly decreased by only the highest dose of 192 IgG-saporin.

Bilateral lesions. Injection of $192 \mathrm{IgG}$-saporin into the basal
Table 1. Effects of 192 IgG-saporin upon passive avoidance performance

\begin{tabular}{lcll} 
Group & $\begin{array}{l}\text { Trials to } \\
\text { criterion }\end{array}$ & $\begin{array}{l}48 \mathrm{hr} \\
\text { retention }\end{array}$ & \% freezing $^{b}$ \\
\hline Control & $1.0 \pm 0.0$ & $820 \pm 241$ & $31.2 \pm 10.5$ \\
Lesion & $1.43 \pm 0.2$ & $984 \pm 135$ & $34.7 \pm 7.9$ \\
\hline
\end{tabular}

Data are expressed as mean \pm SEM.

${ }^{a}$ Expressed as seconds latency to enter the dark compartment, maximum 1200 sec.

${ }^{b}$ Percentage of time spent freezing while in the light compartment.

forebrain significantly decreased ChAT activity in only the frontolateral sensorimotor and parietal-occipital cortex, and within the basal forebrain region (NBM), relative to control levels (Table 3 ).

\section{Neuropeptide levels}

Analysis of the RIA data determined that the concentrations of galanin, somatostatin, or neurotensin in the basal forebrain were not significantly altered by the 192 IgG-saporin. Control and lesion levels (expressed as mean \pm SEM ng/mg protein), respectively, were $28.54 \pm 4.09$ versus $34.61 \pm 4.32$ for somato-

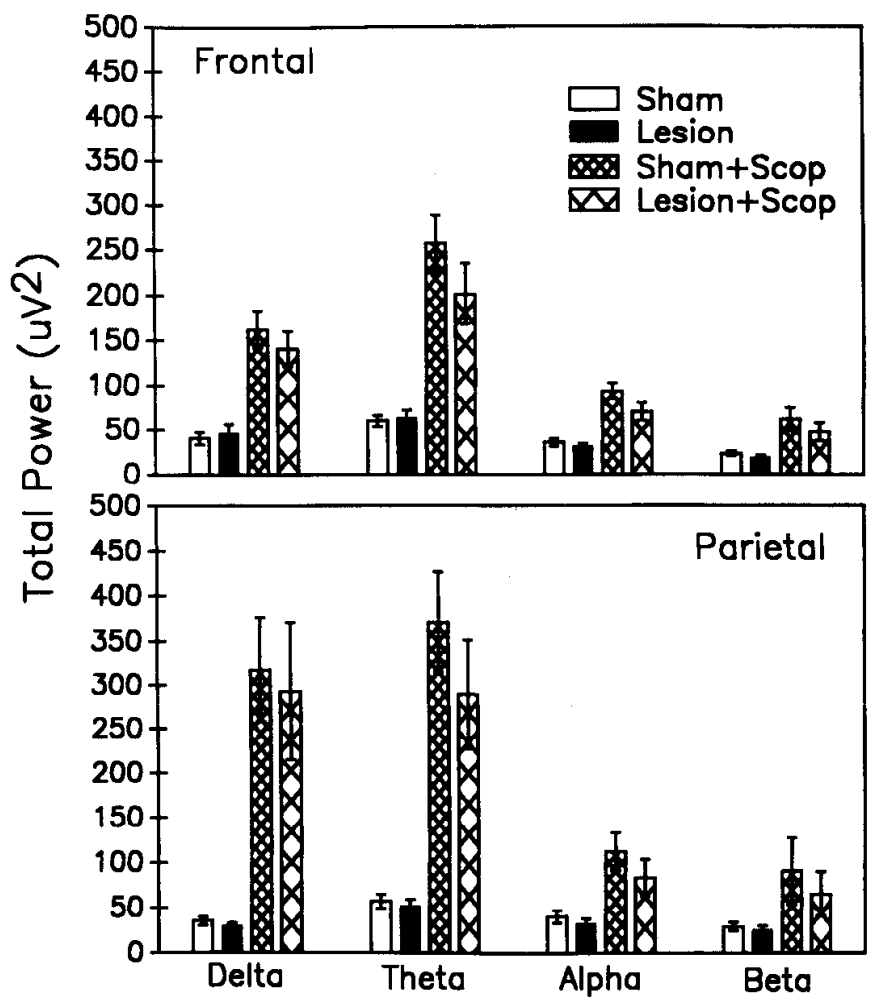

Figure 2. Electrophysiological data analysis. Means \pm SEM of total power $\left(\times 10^{-3}\right)$ recorded over frontal and parietal regions of sham and lesioned hemispheres, before and during treatment with scopolamine $\mathrm{HCl}(1 \mathrm{mg} / \mathrm{kg}$, i.p.). Delta, 1-4 Hz; Theta, 4-8 Hz; Alpha, 8-12 Hz; Beta, 12-20 Hz. Each group contained 18 rats. An ANOVA revealed no significant effect due to the lesions, but a significant effect of the scopolamine treatment across all frequency bands over both frontal and parictal rcgions. Although scopolamine increased total power across all frequency bands, it produced a significantly greater increase in the $\delta$ and $\theta$ frequencies as compared to the $\alpha$ and $\beta$ frequencies. 


\begin{tabular}{|c|c|c|c|c|}
\hline Group & $\begin{array}{l}\text { 192-IgG } \\
(\mathrm{ng} / 30 \mathrm{nl})\end{array}$ & Control & Lesion & $\begin{array}{l}\% \\
\text { Reduction }\end{array}$ \\
\hline \multirow[t]{5}{*}{ Sensorimotor } & 5 & $31.7 \pm 2.5$ & $21.9 \pm 8.7^{*}$ & 31 \\
\hline & 10 & $30.8 \pm 2.8$ & $11.4 \pm 1.6^{* *}$ & 63 \\
\hline & 22.5 & $35.1 \pm 4.9$ & $11.0 \pm 2.7^{* *}$ & 69 \\
\hline & 5 & $34.0 \pm 2.9$ & $25.9 \pm 4.9$ & 24 \\
\hline & 10 & $32.3 \pm 3.9$ & $21.9 \pm 2.5^{*}$ & 32 \\
\hline Parietal-occipital & 22.5 & $35.5 \pm 1.6$ & $14.7 \pm 6.7^{*}$ & 59 \\
\hline \multirow[t]{3}{*}{ Hippocampal } & 5 & $49.7 \pm 1.9$ & $40.3 \pm 6.5$ & 19 \\
\hline & 10 & $36.0 \pm 4.2$ & $31.5 \pm 4.2$ & 13 \\
\hline & 22.5 & $51.6 \pm 0.8$ & $36.1 \pm 2.7^{*}$ & 31 \\
\hline \multirow[t]{3}{*}{ Caudate } & 5 & $202.1 \pm 86.0$ & $164.5 \pm 59.3$ & 18 \\
\hline & 10 & $155.2 \pm 36.4$ & $100.2 \pm 56.0$ & 35 \\
\hline & 22.5 & $243.0 \pm 50.2$ & $145.1 \pm 59.4^{*}$ & 40 \\
\hline \multirow[t]{3}{*}{ Olfactory bulb } & 5 & $26.3 \pm 4.6$ & $28.6 \pm 4.5$ & 9 \\
\hline & 10 & $22.1 \pm 2.9$ & $20.9 \pm 3.6$ & 5 \\
\hline & 22.5 & $28.5 \pm 2.9$ & $19.2 \pm 9.9$ & 33 \\
\hline
\end{tabular}

statin, $1.17 \pm 0.12$ versus $1.28 \pm 0.11$ for galanin, and $2.22 \pm$ 0.15 versus $2.36 \pm 0.16$ for neurotensin.

\section{Histology}

\section{ChAT immunocytochemistry}

The ChAT immunocytochemical studies demonstrated that injections of $192 \mathrm{IgG}$-saporin greatly reduced (by about $50 \%$ ) the density of $\mathrm{Ch} \Lambda \mathrm{T}$-positive cells throughout the basal forebrain, including the substantia innominata and ventral pallidal regions (Fig. 3). ChAT-positive cells were spared within the medial septal area and the vertical and horizontal limbs of the diagonal band of Broca. Injections of $192 \mathrm{IgG}$-saporin produced very little gliosis within the basal forebrain region.

\section{Neuropeptide Y immunocytochemistry}

The NPY immunocytochemical studies demonstrated the presence of NPY-positive cells within the region of the injection of the 192 IgG-saporin (Fig. 4). Although quantitative analyses

\section{Table 3. Cortical choline acetyltransferase activity ${ }^{a}$ in behaviorally} tested rats

\begin{tabular}{llll} 
Group & Control & Lesion & $\begin{array}{l}\% \\
\text { Reduc- } \\
\text { tion }\end{array}$ \\
\hline Sensorimotor & $19.6 \pm 1.1$ & $14.7 \pm 0.6^{* *}$ & 25 \\
Parietal-occipital & $19.6 \pm 0.4$ & $13.6 \pm 0.6^{* *}$ & 31 \\
Hippocampal & $22.8 \pm 3.6$ & $19.2 \pm 1.4$ & 15 \\
Caudate & $49.8 \pm 5.4$ & $42.6 \pm 3.4$ & 14 \\
Olfactory bulb & $14.2 \pm 1.1$ & $14.7 \pm 0.6$ & 4 \\
NBM & $78.7 \pm 5.1$ & $42.7 \pm 3.8^{*}$ & 46
\end{tabular}

Data are presented as mean \pm SEM. Excess ChAT activity in the NBM tissue punch is due to presence of surviving cholinergic cells within the ventral pallidum and caudate nucleus.

${ }^{a}$ Nanomoles of $\mathrm{ACh}$ formed/hr/mg protein

$* p<0.05$ versus control levels.

** $p<0.01$ versus control levels. were not performed, the relative distribution and number of NPY-positive neurons appeared unaltered by injections of 192 IgG-saporin.

\section{NADPH-diaphorase}

NADPH-diaphorase-positive neurons were observed in the vertical and horizontal limbs of the nucleus of the diagonal band, throughout the caudate putamen, and within the fundus striatum, as well as within the bed nucleus of the stria terminalis, the nucleus of the lateral olfactory tract, and the region dorsal to the supraoptic nucleus. The approximate density and distribution of NADPH-diaphorase-positive cells were unchanged by injection of $192 \mathrm{IgG}$-saporin (Fig. 5).

\section{Discussion}

The results of these studies indicate that 192 IgG-saporin effectively and selectively destroyed cholinergic cells in the NBM of rats. Furthermore, the degree of loss of these cholinergic cells in the present study was not sufficient to impair the acquisition or performance of a passive avoidance or food-motivated T-maze alternation task, or to produce a significant slowing of EEG activity.

The biochemical studies found that injections of 192 IgGsaporin significantly decreased the number of cholinergic cells within the basal forebrain, as determined by decreased ChAT activity, the rate-limiting synthetic enzyme in the production of acetylcholine, throughout the neocortex and within the NBM region. The lack of a significant decline in ChAT activity in the hippocampus, olfactory bulbs, and striatum, or in the levels of galanin, somatostatin, or neurotensin, demonstrated that the lesion produced by 192 IgG-saporin was both discrete and restricted to the NBM region as well as selective for cholinergic cells. Only very high doses of 192 IgG-saporin significantly destroyed the cholinergic cells that innervate the olfactory bulbs or hippocampus, or those that are located within the dorsal striatum.

The results from the T-maze task in the present study are 

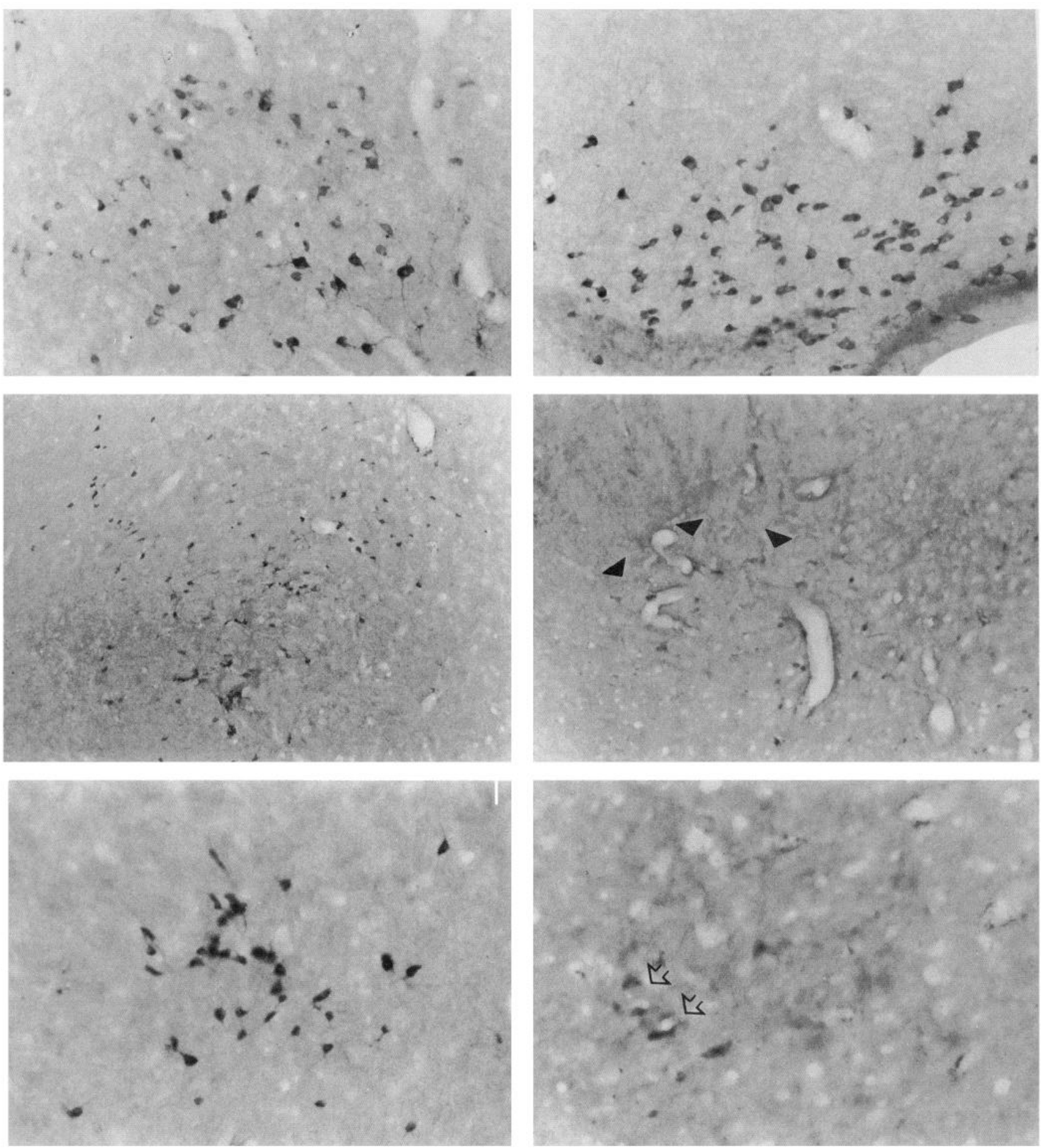

Figure 3. Immunocytochemical study of neurons with choline acetyltransferase (ChAT)-like immunoreactivity. Sections photographed from shamoperated control group rats are shown on the left; sections from lesioned rat are on the right. Top, ChAT-positive cells in the horizontal limb of the diagonal band of Broca. Middle and bottom, Photomicrographs of ChAT-positive cells in the substantia innominata region. Note the loss of magnocellular immunoreactive cells in the section from the lesioned rat (arrowheads). A few shrunken immunoreactive cells survived within the basal forebrain region (arrows).

consistent with previous reports that suggest the destruction of NBM cholinergic cells is not sufficient to impair performance in this task (Wenk et al., 1989, 1992) or similar tasks that require working memory (Markowska et al., 1990). Taken together, these data are consistent with the hypothesis that NBM cholin- ergic cells are not involved directly in the neural processes underlying learning and memory (Muir et al., 1992; Wenk, 1993).

The results from the avoidance experiments suggest that destruction of NBM cholinergic cells is not sufficient to impair passive avoidance acquisition or retention. These results are not 

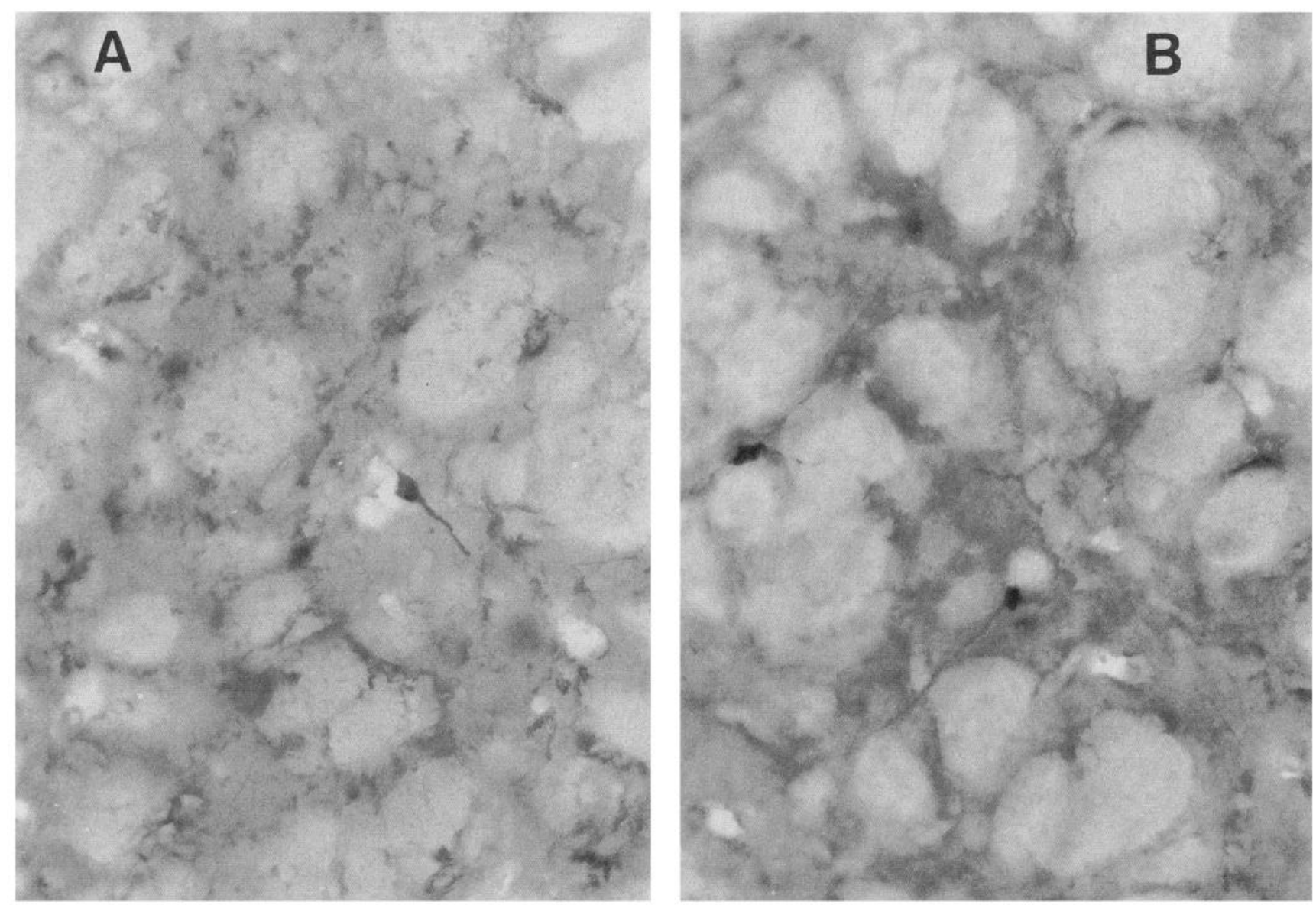

Figure 4. Immunocytochemical study of neurons with neuropeptide Y (NPY)-like immunoreactivity: photomicrographs of NPY-immunostained sections through the basal forebrain of sham-operated control $(A)$ and lesioned $(B)$ rats. The immunoreactive cells shown in both photomicrographs are located immediately dorsal to the anterior commissure within the globus pallidus. NPY-positive cells were observed throughout the basal forebrain and ventral pallidal region in both control and lesioned rats. Numerous immunoreactive cells were present in both fields shown but were outside the plane of focus. Magnification, $100 \times$.

consistent with previous studies that have demonstrated that avoidance training and testing are impaired by NBM lesions (Flicker et al., 1983; Hepler et al., 1985; Whishaw et al., 1985; Dunnett et al., 1987). However, the lack of specificity of the lesions in previous studies precludes a clear understanding of the selective role of NBM cholinergic neurons. The behavioral deficits seen in previous studies might have been due to the destruction of noncholinergic cells or to the loss of cholinergic cells that innervate subcortical areas, such as the hippocampus or amygdala.

The results of the electrophysiological study were unexpected. Many reports have shown that basal forebrain cholinergic cells are responsible for cortical EEG desynchronization or activation (Buzsaki et al., 1988; Riekkinen et al., 1990a,b). For example, in vivo stimulation of the NBM region produced EEG activation that was dependent upon muscarinic receptor stimulation (Metherate et al., 1992; Baghdoyan et al., 1993). Application of acetylcholine or its pharmacological agonists (Vanderwolf et al., 1993) effectively depolarized cortical neurons and shifted the EEG power spectrum from large-amplitude slow activity to lowamplitude fast activity (Metherate et al., 1992). Furthermore, in rats with NBM lesions produced by injections of excitotoxins, such as IBO, QUIS, or kainic acid, or in humans with Alzheimer's disease, the loss of cholinergic cells has been correlated with the widespread appearance of cortical slow-wave activity and a decline in the amount of higher-frequency EEG activity (Rae-Grant et al., 1987; Soininen et al., 1993; Vanderwolf et al., 1993). In the present study, the selective loss of NBM cholinergic cells was not associated with a significant slowing of EEG activity. However, a significant shifting to lower EEG frequencies was seen in all rats given scopolamine. The results of our investigation using scopolamine confirmed that the electrophysiological approach used in the present study was sensitive to shifts in the EEG power spectrum to lower frequencies. The EEG slowing previously reported in NBM-lesioned rats (Buzsaki et al., 1988; Riekkinen et al., 1990a,b) might have been due to the loss of noncholinergic basal forebrain cells or to the destruction of nearby structures involved in the control of cortical EEG, for example, the reticular nucleus of the thalamus. NBM acetylcholine cells may be involved with activation of the neocortex, but their selective destruction may not be sufficient to slow overall EEG activity. Scopolamine's effects upon the EEG frequency spectrum may be due to its effects upon cholinergic neurons elsewhere in the brain that may also influence cortical activation, for example, cholinergic neurons within the midbrain reticular formation (i.e., Ch groups 5 and 6) that innervate the thalamic nuclei (Steriade and Buzsaki, 1990). In Alzheimer's disease, EEG slowing may be more closely related to abnor- 

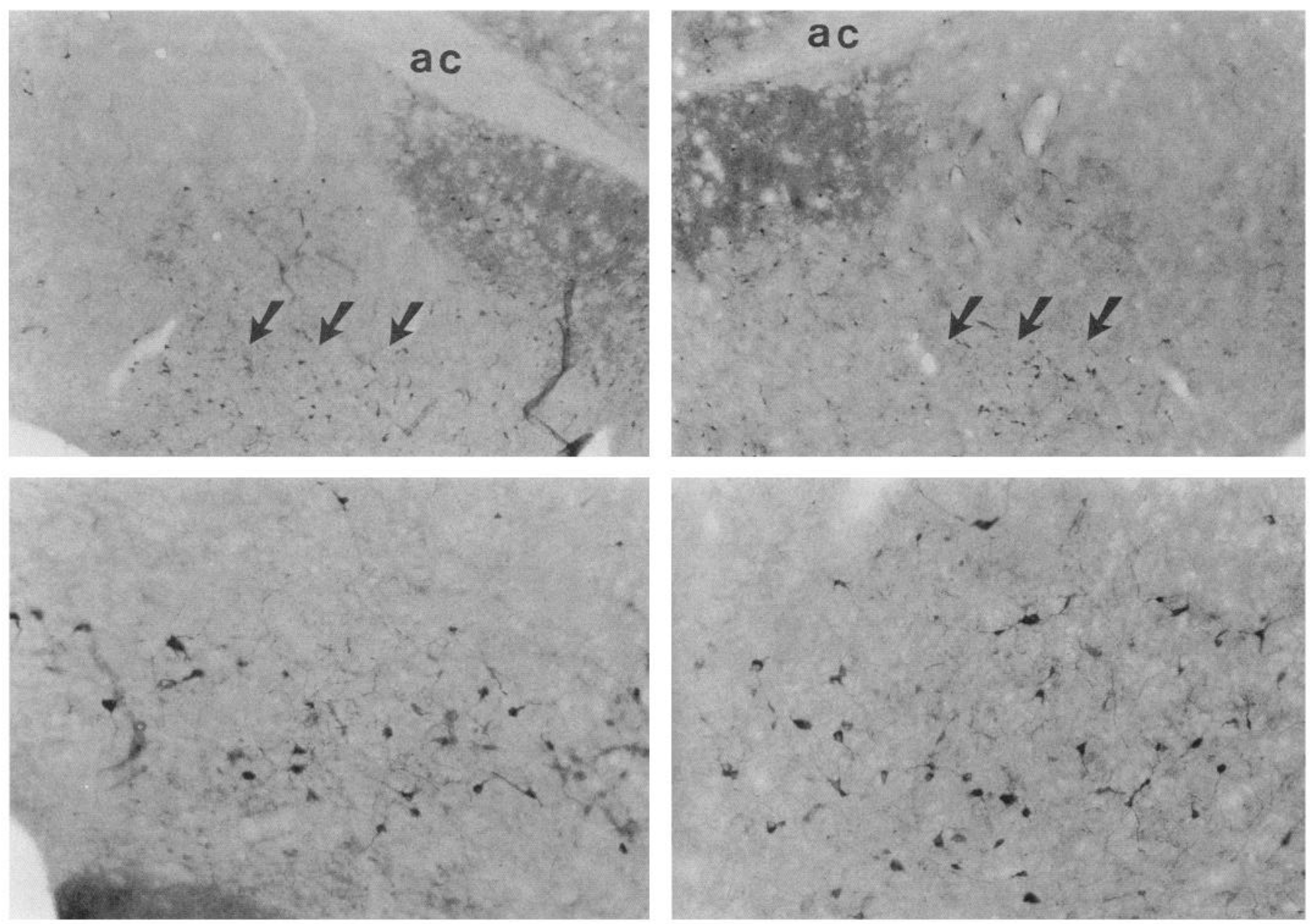

Figure 5. Histochemical study of neurons stained for NADPH-diaphorase activity: low- $(20 \times$, top $)$ and high- $(40 \times$, bottom) magnification photomicrographs of the horizontal limb of the diagonal band of Broca from a control (left side) and lesioned (right side) rat. ac, anterior commissure. Arrows indicate the region where NADPH-diaphorase-positive neurons are concentrated. NADPH-diaphorase-positive neurons were observed throughout the basal forebrain region in both control and lesioned rats.

malities in cerebral glucose metabolism (Haxby et al., 1985) or global neurodegeneration as well as the specific loss of cholinergic neocortical afferents. The precise electrophysiological consequences of the selective loss of NBM cholinergic cells in Alzheimer's disease or in rats with NBM lesions remain to be fully investigated. We have recently examined the effects of larger $(20 \mathrm{ng}$ in $0.06 \mu \mathrm{l})$ amounts of $192 \mathrm{IgG}$-saporin in the basal forebrain upon the EEG power spectrum while rats were in both slow-wave and paradoxical sleep. The results were similar to those reported here; that is, there were no significant changes in fast- or slow-wave EEG power in either sleep phase (J. D. Stoehr and G. L. Wenk, unpublished observations).

The lack of an effect upon performance in the behavioral tasks and upon cortical EEG activity may be due to the fact that 192 IgG-saporin did not completely remove all cholinergic innervation from the neocortex. A threshold level of NBM cholinergic cell loss may be necessary in order to see a memory impairment. However, previous studies using the neurotoxins IBO and kainic acid have shown that far smaller depletions of cortical ChAT activity than were achieved in the present study can impair spatial memory (Wenk et al., 1989, 1992) and slow cortical EEG activity (Buzsaki et al., 1988; Riekkinen et al., 1990a,b). Unfortunately, IBO and kainic acid are not selective for acetyl- choline neurons; the memory impairments and EEG changes might have been related to the nonspecific cell loss associated with these toxins (Wenk et al., 1992). Therefore, the question of whether there is a threshold level of NBM cholinergic cell loss necessary to impair memory or slow cortical EEG remains to be explored.

Single-unit recording studies performed on primates have suggested that the cholinergic cells in the NBM may evaluate afferent sensory stimuli for either significance, degree of novelty or familiarity, or association with a subsequent reward (Wilson and Rolls, 1990). NBM neurons (probably cholinergic) respond independently of the sensory properties of a stimulus, the type of reinforcer associated with the stimulus, and the type of response required to obtain the reinforcer. The neurons respond to stimuli that have become predictors for the availability of reward, even though initially the stimuli were neutral. The activity pattern of NBM neurons suggests that these neurons have access to information about the reinforcement value of a stimulus that is dependent upon past experience (Wilson and Rolls, 1990). Studies by Richardson and Delong (1991) have shown that NBM neurons are active when a monkey has obtained all of the necessary information for making a behavioral response that will lead to a reward. Taken together with the results of the 
present study, these results are consistent with the hypothesis that NBM cholinergic neurons have access to memories, but are not actively involved in the acquisition or consolidation of those memories. This conclusion may explain why the destruction of NBM cholinergic cells in rats does not produce a consistent or long-lasting impairment in tasks that are selective for learning and memory abilities (Dunnett et al., 1987; Robbins et al., 1989; Wenk et al., 1989, 1992; Markowska et al., 1990; Page et al., 1991).

A recent study compared the memory and attentional deficits associated with basal forebrain lesions in monkeys (Voytko et al., 1994). Five monkeys were given large (13-19 injections of ibotenic acid per hemisphere) lesions throughout the entire basal forebrain region, including the medial septum, diagonal band of Broca, and nucleus basalis of Meynert. The monkeys were trained and tested pre- and postoperatively in an assortment of behavioral tasks of varying difficulty that were sensitive to and selective for learning and memory deficits, including delayed nonmatch to sample, delayed response, simple or concurrent object discriminations, spatial discrimination, or discrimination reversal. Performance was not impaired in any task, although the lesioned monkeys were more sensitive to a low dose of scopolamine. In contrast, lesioned monkeys were impaired in an attention task that tested spatial orienting ability. A quite similar impairment in attentional ability has been described in patients with Alzheimer's disease (Parasuraman et al., 1992). Therefore, the basal forebrain cholinergic system may be involved in attentional rather than mnemonic neural processes.

In conclusion, the results of the present study suggest that the selective destruction of cholinergic neurons is now possible and that past assumptions about the role of NBM cholinergic neurons in learning and memory (for reviews, see Olton and Wenk, 1987; Wenk and Olton, 1987) may be erroneous. The nonspecific destruction of noncholinergic basal forebrain neurons by glutamate analogs, for example, kainic acid, QUIS, IBO, NMDA, and AMPA, might have produced significant memory deficits that were not dependent upon the loss of NBM cholinergic cells. In contrast, the destruction of medial septal cholinergic cells, which send afferents to the hippocampus, more reliably impairs learning and memory (for review, see Wenk and Olton, 1987). Finally, these data are also consistent with previous hypotheses (Wenk et al., 1984, 1993; Muir et al., 1992) that cholinergic cells in the NBM and media septal area may be differentially involved in the neural processes that underlie attentional abilities and memory, respectively.

\section{References}

Baghdoyan HA, Spotts JL, Snyder SG (1993) Simultaneous pontine and basal forebrain microinjections of carbachol suppress REM sleep. J Neurosci 13:229-242.

Bartus RT, Dean RL, Beer B, Lippa AS (1982) The cholinergic hypothesis of geriatric memory dysfunction. Scicnce 217:408-417.

Book AA, Wiley RG, Schweitzer JB (1992) Specificity of 192 IgGsaporin for NGF receptor-positive cholinergic basal forebrain neuron in the rat. Brain Res 590:350-355.

Buzsaki G, Bickford RG, Ponomareff G, Thal LJ, Mandel R, Gage FH (1988) Nucleus basalis and thalamic control of neocortical activity in the freely moving rat. J Neurosci 8:4007-4026.

Candy JM, Perry RH, Thompson JE, Oakley AE (1985) Neuropeptide localization in the substantia innominata and adjacent regions of the human brain. J Anat 140:309-327.

Dunnett SB, Whishaw IQ, Jones GH, Bunch ST (1987) Behavioral, biochemical and histochemical effects of different neurotoxic amino acids injected into nucleus basalis magnocellularis of rats. Neuroscience 20:653-669.
Dunnett SB, Everitt BJ, Robbins TW (1991) The basal forebraincortical cholinergic system: interpreting the function consequences of excitotoxic lesions. Trends Neurosci 14:494-501.

Etherington R, Mittleman G, Robbins IW (1987) Comparative effects of nucleus basalis and fimbria-fornix lesions on delayed matching and alternation tests of memory. Neurosci Res Commun 1:135-143.

Everitt BJ, Robbins TW, Evenden JL, Marston HM, Jones GH, Sirkia TE (1987) The effects of excitotoxic lesions of the substantia innominata, ventral and dorsal globus pallidus on the acquisition and retention of a conditional visual discrimination: implications for cholinergic hypotheses of learning and memory. Neuroscience 22:441469.

Flicker C, Dean RL, Watkins DL, Fisher SK, Bartus RT (1983) Behavioral and neurochemical effects following neurotoxic lesions of a major cholinergic input to the cerebral cortex in the rat. Pharmacol Biochem Behav 18:973-981.

Fonnum F (1969) Radiochemical microassays for the determination of choline acetyltransferase and acetylcholinesterase activities. Biochem J 1 15:465-472.

Haxby JV, Duara R, Grady CL, Cutler NR, Rapoport SI (1985) Relations between neuropsychological and cerebral metabolic asymmetries in early Alzheimer's disease. J Cereb Blood Flow Metab 5:193200.

Hepler DJ, Wenk GL, Cribbs BL, Olton DS, Coyle JT (1985) Memory impairments following basal forebrain lesions. Brain Res 346:8-14.

Lowry $\mathrm{OH}$, Rosenbrough NJ, Farr $\Lambda \mathrm{L}$, Randall RJ (1951) Protcin measurement with folin phenol reagent. J Biol Chem 193:265-275.

Markowska AL, Wenk GL, Olton DS (1990) Nucleus basalis magnocellularis and memory: differential effects of two neurotoxins. Behav Neural Biol 54:13-26.

Mesulam M-M, Mufson EJ, Levey AI, Wainer BH (1983) Cholinergic innervation of cortex by the basal forebrain: cytochemistry and cortical connections of the septal area diagonal band nuclei, nucleus basalis (substantia innominata) and hypothalamus in the rhesus monkeys. J Comp Neurol 214:170-197.

Metherate R, Cox CL, Ashe JH (1992) Cellular bases of neocortical activation: modulation of neural ascillations by the nucleus basalis and endogenous acetylcholine. J Neurosci 12:4701-4711.

Muir JL, Dunnett SB, Robbins TW, Everitt BJ (1992) Attentional functions of the forebrain cholinergic systems: cffects of intraventricular hemicholinium, physostigmine, basal forebrain lesions and intracortical grafts on a multiple-choice serial reaction time task. Exp Brain Res 89:611-622.

Nilsson OG, Leanza G, Rosenblad C, Lappi DA, Wiley RG, Bjorklund A (1992) Spatial learning impairments in rats with selective immunolesion of the forebrain cholinergic system. Neuroreport 3:10051008 .

Olton DS, Wenk GL (1987) Dementia: animal models of the cognitive impairments produced by degeneration of the basal forebrain cholinergic system. In: Psychopharmacology: the third generation of progress (Meltzer HY, ed), pp 941-953. New York: Raven.

Page KJ, Everitt BJ, Robbins TW, Marston HM, Wilkinson LS (1991) Dissociable effects on spatial maze and passive avoidance acquisition and retention following AMPA- and ibotenic acid-induced excitotoxic lesions of the basal forebrain in rats: differential dependence on cholinergic neuronal loss. Neuroscience 43:457-472.

Parasuraman R, Greenwood PM, Haxby JV, Grady CL (1992) Visuospatial attention in dementia of the Alzheimer type. Brain 115: 711-733.

Rae-Grant A, Blume W, Lau C, Hachinski VC, Merskey H (1987) The electroencephalogram in Alzheimer-type dementia. Arch Neurol 44: $50-54$.

Richardson RT, DeLong MR (1991) Functional implications of tonic and phasic activity changes in nucleus basalis neurons. In: Activation to acquisition: functional aspccts of the basal forebrain cholinergic system (Richardson RT, ed), pp 135-166. Boston: Birkhauser.

Riekkinen M, Riekkinen P, Riekkinen P Jr (1991) Comparison of quisqualic and ibotenic acid nucleus basalis magnocellularis lesions on water-maze and passive avoidance performance. Brain Res Bull 27:119-123.

Riekkinen P Jr, Sirvio J, Miettinen R, Riekkinen P (1990a) Interaction between raphe dorsalis and nucleus basalis magnocellularis in the regulation of high-voltage spindle activity in rat neocortex. Brain Res 526:31-36.

Riekkinen P Jr, Sirvio J, Riekkinen P (1990b) Similar memory im- 
pairments found in medial septal-vertical diagonal band of broca and nucleus basalis lesioned rats: are memory defects induced by nucleus basalis lesions related to the degree of nonspecific subcortical cell loss? Behav Brain Res 37:81-88.

Robbins TW, Everitt BJ, Marston HM, Wilkinson J, Jones GH, Page KJ (1989) Comparative effects of ibotenic acid-and quisqualic acidinduced lesions of the substantia innominata on attentional function in the rat: further implications for the role of the cholinergic neurons in the nucleus basalis in cognitive processes. Behav Brain Kes 35: 221-224.

Sarter M, Dudchenko P (1991) Dissociative effects of ibotenic and quisqualic acid-induced basal forebrain lesions on cortical acetylcholinesterase-positive fiber density and cytochrome oxidase activity. Neuroscience 41:729-738.

Scherer-Singler U, Vincent SR, Kimura H, Mcgeer EG (1983) Demonstration of a unique population of neurons NADPH-diaphorase histochemistry. J Neurosci Methods 9:229-234.

Soininen H, Partanen J, Jousmaki V, Helkala E-L, Vanhanen M, Majuri S, Kaski M, Hartikainen P, Riekkinen P (1993) Age-related cognitive decline and electroencephalogram slowing in Down's syndrome as a model of Alzheimer's disease. Neuroscience 53:57-63.

Steriade M, Buzsaki G (1990) Parallel activation of thalamic and cortical neurons by brainstem and basal forebrain cholinergic systems. In: Brain cholinergic systems (Steriade M, Biesold D, eds), pp 3-62. New York: Oxford UP.

Stewart DJ, MacFabe DF, Vanderwolf CH (1984) Cholinergic activation of the electrocorticogram: role of substantia innominata and effects of atropine and quinuclidinyl henzilate. Brain Res 322:219232.

Vanderwolf CH, Raithby A, Snider M, Cristi C, Tanner C (1993). Effects of some cholinergic agonists on neocortical slow wave activity in rats with basal forebrain lesions. Brain Res Bull 31:515-521.

Voytko ML, Olton DS, Richardson RT, Gorman LK, Tobin JR, Price DL (1994) Basal forebrain lesions in monkeys disrupt attention but not learning and memory. J Neurosci 14:167-186.
Wenk GL (1993) A primate model of Alzheimer's disease. Behav Brain Res 57:117-122.

Wenk GL, Olton DS (1987) Basal forcbrain cholincrgic neurons and Alzheimer's disease. In: Animal models of dementia: a synaptic neurochemical perspective (Coyle JT, ed), pp 81-101. New York: Liss.

Wenk G, Hepler D, Olton D (1984) Behavior alters the uptake of $\left[{ }^{3} \mathrm{H}\right]$ choline into acetylcholinergic neurons of the nucleus basalis magnocellularis and medial septal area. Behav Brain Res 13:129-138.

Wenk GL, Markowska AL, Olton DS (1989) Basal forebrain lesions and memory: alterations in neurotensin, not acetylcholine, may cause amnesia. Behav Neurosci 103:765-769.

Wenk GL, Harrington CA, Tucker DA, Rance NE, Walker LC (1992) Basal forebrain neurons and memory: a biochemical, histological and behavioral study of differential vulnerability to ibotenate and quisqualate. Behav Neurosci 106:909-923.

Whishaw IQ, O'Connor WT, Dunnett SB (1985) Disruption of central cholinergic systems in the rat by basal forebrain lesions or atropine: effects on feeding sensorimotor behavior, locomotor activity and spatial navigation. Behav Brain Res 17:103-115.

Wiley RG (1992) Neural lesioning with ribosome inactivating proteins: suicide transport and immunolesioning. Trends Neurosci 15: 285-290.

Wiley RG, Lappi DA (1993) Preparation of anti-neuronal immunotoxins for selective neural lesioning. Elsevier Neurosci Protocols 1: in press.

Wiley RG, Oeltmann TN, Lappi DA (1991) Immunolesioning: selective destruction of neurons using immunotoxin to rat NGF receptor. Brain Res 562:149-153.

Wilson FAW, Rolls ET (1990) Neuronal responses related to the novelty and familiarity of visual stimuli in the substantia innominata, diagonal band of Broca and periventricular region of the primate basal forebrain. Exp Brain Res 80:104-120. 